Meulders concludes his book with three incisive chapters on the aesthetics of music. In one he deals with the Pythagorean legacy, especially the idea that mathematical relationships were the basis of harmony and tone. In the second he considers 'the musical ear', demonstrating that findings in auricular physiology, particularly Italian anatomist Alfonso Corti's discovery in 1851 of fibres that function as acoustical sensor cells in the cochlea, had complicated the aesthetics of sound.

This chapter is a triumph of compression of a vast province of physiology and aesthetics into a few pages. Surveying the musicological terrain from the argument between Jean-Philippe Rameau and Jean le Rond d'Alembert to Johann Sebastian Bach and Andreas Werckmeister, and on to Mozart and Mendelssohn, Meulders pauses to explain how Helmholtz the empiricist understood

\section{NATURE.COM}

For more on German

science history, see: go.nature.com/R5K70w music theory and aesthetics as a grand unifier. Musical sounds, he thought, can only be understood as great art by combining anatomy, physiology, philosophy and psychology. The third of these chapters meditates on Helmholtz's nostalgia, intuition and memory - an odd amalgam, the breadth of which adds to Meulders's claim for Helmholtz's genius.

Meulders stitches together the thoughts of a lifetime into his slim book. He doesn't surrender his admiration - at times verging on hero worship - despite the occasional critique. The approach is hit-and-miss and does not amount to the much-desired extended interpretation unifying Helmholtz's physiology and aesthetics, but it is a brave start.

Meulders sums up his subject thus: "With his will to unify so many different scientific disciplines in a coherent entity, he proved once again his veritable gluttony for science and knowledge." Some may find Meulders equally gluttonous, but his book demonstrates that Helmholtz was indeed a polymath par excellence.

George Rousseau is a professor of history and co-director of the Centre for the History of Childhood, University of Oxford, Oxford, OX1 4AU, UK. He is author of Nervous Acts. e-mail:george.rousseau@magd.ox.ac.uk

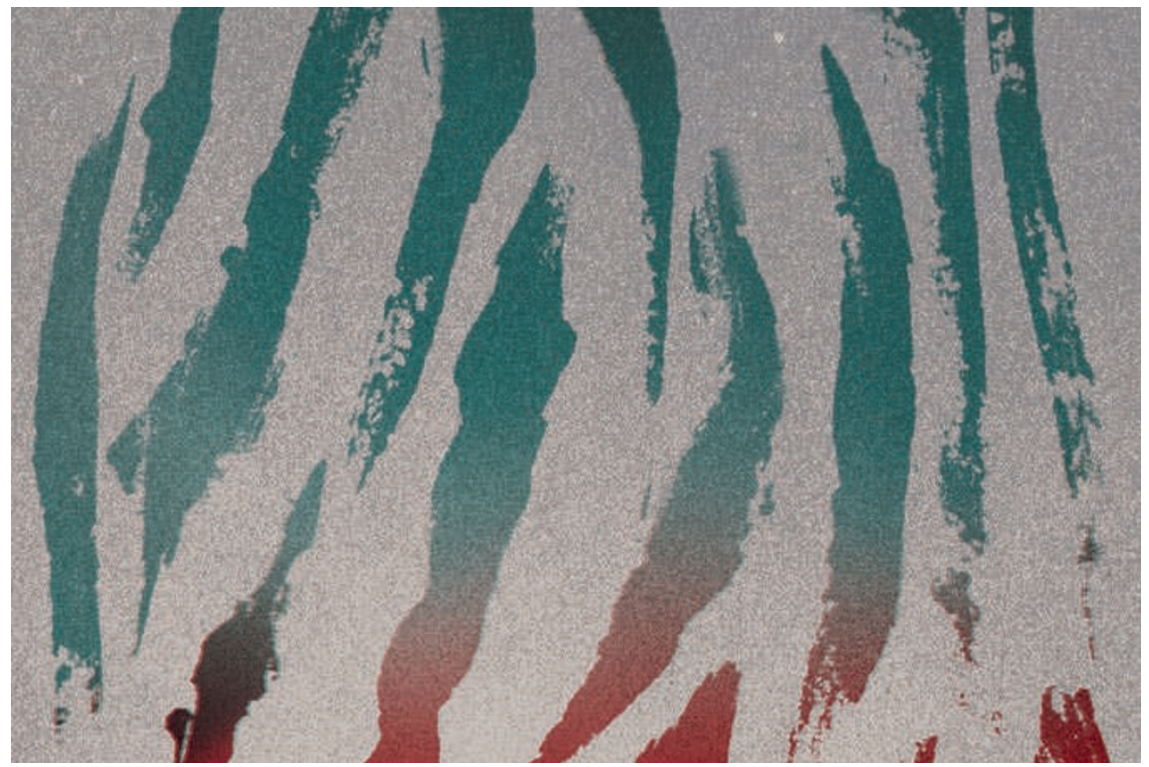

ECOLOGY

\title{
Conservation thriller earns its stripes
}

\section{A travelogue about tiger poaching in Russia's far east opens up a new genre, discovers Geoff Marsh.}

$\mathrm{Y}$ uri Trush steadily points his camera at the stubs of bone protruding from a pair of thin rubber boots lying in the blood-speckled snow. As the leader of an Inspection Tiger anti-poaching unit, his job now is to piece together the details of Vladimir Markov's run-in with the tiger. Judging by the whimpering of Trush's dog, the big cat in question remains close by, among the trees.

Inspection Tiger is a government agency that was set up to combat poaching in Primorskiy Kray (or Primorye) - an area the size of Washington state in the far east of Russia, bordered by China and North Korea. Trush's team travels in a decommissioned army truck, armed with knives, pistols and semiautomatic rifles. Their mission is to intercept poachers and to resolve

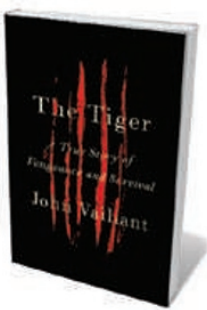

The Tiger: A

True Story of Vengeance and Survival JOHN VAILLANT Sceptre/Alfred Knopf: 2010. 352 pp. $£ 18.99 / \$ 26.95$ of far north. A peculiar mix of hardy alpine

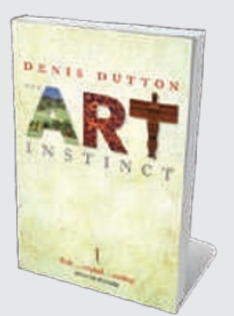

The Art Instinct

Denis Dutton (Oxford Univ. Press, 2010; £9.99)

Art appreciation has an evolutionary basis, according to philosopher Denis Dutton. The basic elements of aesthetic taste are similar across cultures and are part of our evolutionary heritage rather than being socially constructed, he claims provocatively.

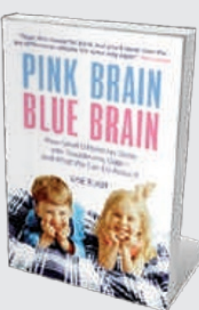

Pink Brain, Blue Brain

Lise Eliot (OneWorld, 2010; £12.99)

Neuroscientist Lise Eliot marshals the latest evidence to show that social pressures are the main cause of behaviour differences between boys and girls. Although small gender variations are apparent at birth, they grow as our plastic brains quickly become modified by experiences. 
and lush tropical plants shelter an equally varied assortment of animals - timber wolves compete with leopards for fanged musk deer.

The Amur (or Siberian) tiger is one of nine recognized subspecies, three of which have gone extinct in the past century. Their numbers in Russia have declined severely during this time. The period 1992-94 alone saw onequarter of the country's wild tiger population killed and sold, mostly to China for use in traditional medicine. Last year, the international Siberian Tiger Monitoring Programme reported a significant drop in numbers in the past decade; now, probably fewer than 400 tigers remain in the Russian far east. Poaching is thought to be the main factor in their decline.

The tension between humans and tigers first arose from a shared appetite for meat and large territories, says Vaillant. Add to this the poverty of many of the inhabitants of Primorye after perestroika in the late 1980s and the temptations of a lucrative black market for tiger parts, and cases such as Markov's become inevitable. People must poach or starve.

Vaillant weaves his story using an evolutionary and cultural context. Our relationship with big cats began with us scavenging their kills, he suggests. Predation was of secondary concern, with humans taking the risk of being attacked in order to scavenge, and both species largely leaving each other alone. This evolutionary treaty to do no harm is reflected in the behaviours of

picture of the Amur tigers' demise in northeast Asia. Vaillant points out that the animal's fate is entirely in our hands. Its conservation represents more than just the survival of this charismatic predator: because it is a keystone species, an environment in which a tiger thrives is necessarily a healthy one. The very presence of tigers at the top of an ecosystem confirms that it is intact. Vaillant describes the tiger as "an enormous canary in the biological coal mine".

Heroes such as Trush and his team are as endangered as the tigers they protect, owing to severe cuts in staff and funding. Restoring such agencies,

the native hunters in Russia's far east, and in the relationship of Kalahari bushmen with lions: both groups avoid confrontation with the cats, and are able to live safely alongside them.

When a Primorye poacher goes against this treaty, the locals believe that the tiger will be purposefully vengeful. Markov reportedly shot at the tiger that killed him days before the attack; the tiger then waited at his cabin for him to return. Although clearly anthropomorphized, this theory of feline vendetta is a haunting notion.

The Tiger does more than paint a gloomy Vaillant says, will be key to the survival of the Amur tiger and its prey.

This epic story helps to raise awareness of conservation issues in the Russian far east, yet its reach is greater: actor Brad Pitt and film director Darren Aronofsky are currently adapting The Tiger for the big screen. This new genre of conservation thriller could be a powerful way of generating interest in the plight of species that are on the brink of extinction.

Geoff Marsh is a former ecologist who is now a multimedia producer at Nature. 